\title{
OUTCOME OF THE POSTERIOR APPROACH IN MANAGEMENT OF POSTERIOR TIBIAL PLATEAU FRACTURES: CASE SERIES STUDY
}

\author{
Eltemamy M. ${ }^{1}$ Soliman ${ }^{1}{ }^{1}, A L-K e r s h ~ M^{1}$, , Mahran M. ${ }^{1}$,EL-Sobky T. ${ }^{1}$.
}

Orthopaedic Surgery

Department, Faculty of

Medicine, Ain Shams

University, Egypt.

Corresponding Author:

Mahmoud Eltemamy

Mobile: 01005190240

E-mail:

mahmoud.temamy@gmail.com

Received: 20/7/2020

Accepted: 11/8/2020

Online ISSN: 2735-3540

\begin{abstract}
:
Background: Complex tibial plateau fracture management remains clinically challenging. In recent years, a "three-column fixation" technique was developed to treat the multiplanar complex tibial plateau fractures, which is based on three-dimensional understanding of the fractures. The direct posterior approach to posteromedial fractures of the tibial plateau, with the patient in a prone position, has been used to overcome limitations related to conventional posteromedial approaches. The posterior approach allows for fracture reduction by hyperextension of the knee through axial traction over a surgical bump.
\end{abstract}

Objective: Evaluate the clinical and radiologic efficacy of use of posterior approaches to tibial plateau fractures whether alone or combined with other approaches sequentially or staged for complex tibial plateau fractures with posterior involvement.

Patients and methods: this study included twenty seven consecutive patients with tibial plateau fractures involving the posterior column in Orthopaedic Department, Ain Shams University Hospitals-Egypt in the period between August 2016 and August 2018. Cases underwent Lobenhoffer approach for the posteromedial fragment, or posterolateral approach with or without fibula osteotomy for posterolateral fragment fixation. Patients were evaluated radio logically immediately postoperative, at 3, 6, 12, 18 months by serial anteroposterior and lateral $x$ - rays of knee with comparison with preoperative data.

Results: The cases were 4 femalesand 23 males, with age range between $18-4 \bar{\sigma}$ years. There was a significant improvement after the surgery regarding the following parameters; pain, extension lag, antero-posterior stability, medio-lateral stability, total range of Flexion, alignment (Varus \& Valgus) and Walking distribution. The results showed that $7.4 \%$ of the patients had Knee society score (KSS) of 70, 18.5\% of the patients had a score of 75, while $29.6 \%$ of the patients had a score of 80 , only $3.7 \%$ of the patients had a score of 85; in addition to $11.1 \%$ of the patients had a score of $90,3.7 \%$ of the patients had a score of 95 , and $25.9 \%$ of the patients had a score of 100.

Conclusion: Posterior approaches to tibial plateau fractures whether alone or combined with other approaches was associated with good outcomes along the duration of postoperative follow up and should be advised for management of tibial plateau fractures.

Key words: tibial plateau, Lobenhoffer, posterior approach, Schatzker classification.

\section{INTRODUCTION:}

Complex tibial plateau fracture management is clinically challenging. These fractures are usually described as Schatzker Type V and VI or as a 41- C type injury when using the $\mathrm{AO} /$ Orthopaedic Trauma 
Association classification ${ }^{(1,2)}$. Dual plating is usually recommended as the definite fixation for this kind of fracture ${ }^{(3,4)}$. However, this technique sometimes is not applicable to work in fractures with multiplanar articular comminution. This is especially true when there is posterior shearing or a coronal fracture $e^{(5,6)}$.

Traditionally, the treatment for tibial plateau fractures is based on twodimensional classification systems. Several authors have noted computed tomography (CT) based three-dimensional consideration of the fracture pattern was important in the treatment of tibial plateau fractures. In recent years, a "three-column fixation" technique was developed to treat the multiplanar complex tibial plateau fractures, which is based on three-dimensional understanding of the fractures ${ }^{(7,8)}$.

The three-column classification is described by Lou et al. According to this classification, one independent articular depression with a break of the column wall is defined as a fracture of the relevant column, pure depression in any three columns was classed as zero column, and pure split and split with depression were classified according to the column involved as per the CT scans ${ }^{(9,10)}$.

Complex bicondylar tibial plateau fractures follow a regular pattern, which is not represented in 2-dimensional fracture classifications. A two-incision techniques starting with the reduction of the posteromedial edge results in accurate fracture reduction with low complication rates and excellent knee function ${ }^{(11)}$.

Fractures of the tibial plateau that have an associated, displaced posteromedial fracture pattern are difficult to reduce and fix adequately through conventional surgical approaches. The direct posterior approach to posteromedial fractures of the tibial plateau, with the patient in a prone position, has been used to over-come limitations related to conventional posteromedial approaches. The posterior approach allows for fracture reduction by hyperextension of the knee through axial traction over a surgical bump. The technique allows the direct visualization of posteromedial fractures of the tibial plateau without the need for dissection of the neurovascular bundle, and for placement of an antiglide buttress plate at the apex of the posteromedial fracture fragment ${ }^{(12)}$.

Posterolateral transfibular neck approach was developed as an alternative to the anterolateral approach to the tibial plateau for the treatment of two fracture subtypes: depressed and split depressed fractures in which the comminution and depression are located in the posterior half of the lateral tibial condyle. This approach exposes the posterolateral aspect of the tibial plateau between the posterior margin of the iliotibial band and the posterior cruciate ligament. This approach allows lateral buttressing of the lateral tibial plateau and may be combined with a simultaneous posteromedial and/or anteromedial approach to the tibial plateau ${ }^{(13)}$. Alternatively a modification of the standard posterolateral approach was developed without fibular osteotomy ${ }^{(14)}$.

This prospective interventional study was conducted to evaluate the clinical and radiologic efficacy of use of posterior approaches to tibial plateau whether alone or combined with other approaches sequentially or staged for complex tibial plateau fractures with posterior involvement.

\section{PATIENTS AND METHODS:}

This is a prospective interventional study conducted in Orthopaedic Department, Ain Shams University Hospitals-Egypt in the period between August 2016 and August 2018.Twenty seven consecutive patients with tibial plateau fracture involving the posterior column were included with the following criteria; both sexes, skeletally 
mature patients with closed tibial plateau recent fracture types V and VI (within three weeks of injury) according to Schatzker classification with posterior column involvement as demonstrated on CT scans and recent fractures. The patients with the following conditions were excluded; active infection of the joint, patients with fracture or soft tissue configurations not amenable for internal fixation, Schatzker classification other than types V and VI, patients blow 18 years of age (skeletally immature), other serious leg injuries sufficient to affect outcome at final follow up as, peripheral angiopathy, neuropathy in the injured limb, impaired cognition, morbid obesity and compartment syndrome.

\section{Preoperative evaluation:}

All patients had given informed consent, and the study protocol was approved by the Institutional Review Board in Ain-Shams University.

All cases were subjected to careful history taking and assessment of the patients, its duration with special emphasis on the mode of trauma and mechanism of injury. A detailed physical examination of affected limb with special emphasis on skin condition soft tissue status, edema and current vascular status and any pre-injury disabilities, surgery or neurovascular compromise.All the patients were evaluated pre-operatively through a routine clinical trauma evaluation will be carried out Soft tissue injury severity will be assessed according to Oestern and Tscherne classification ${ }^{(15)}$. The classification has demonstrated an adequate level of intraobserver and interobserver agreement in tibial plateau and tibial pilon fractures ${ }^{(16)}$.The following radiological techniques were conducted for all the cases including plain $\mathrm{x}$ ray: knee (AP \& LAT), traction radiographs if required, C.T scans axial with reformatted sagittal, coronal and 3D images.

\section{Operative technique:}

Operative planning after CT scans for posterior column involvement, and location of theses fragments, in case of posteromedial fragment fixation; prone patient position was utilised, with use of Lobenhoffer approach for the posteromedial fragment which can be extended to extensile Lobenhoffer ${ }^{(17)}$.

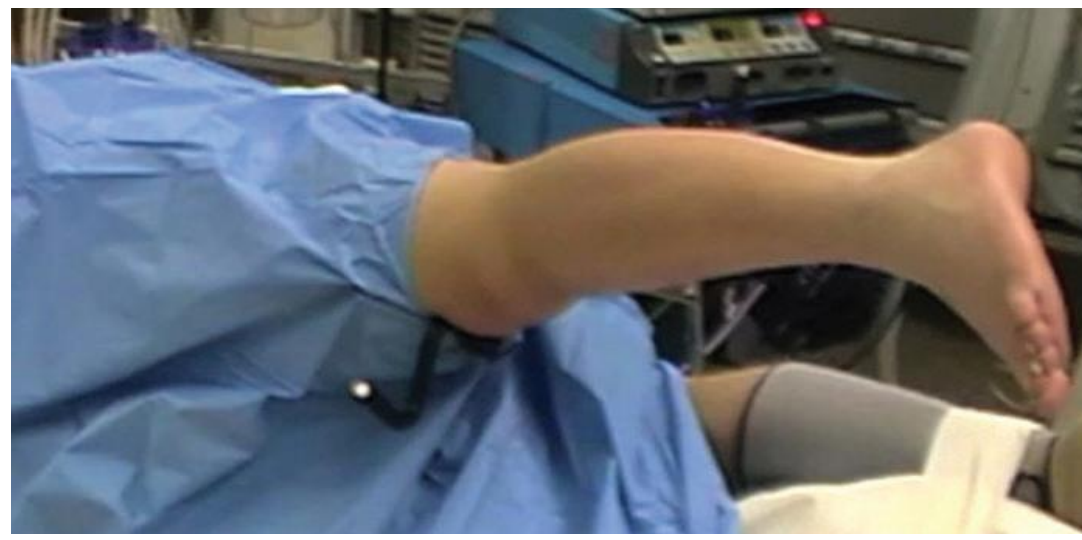

Figure (1): patient in a prone position at the beginning of the surgery. 


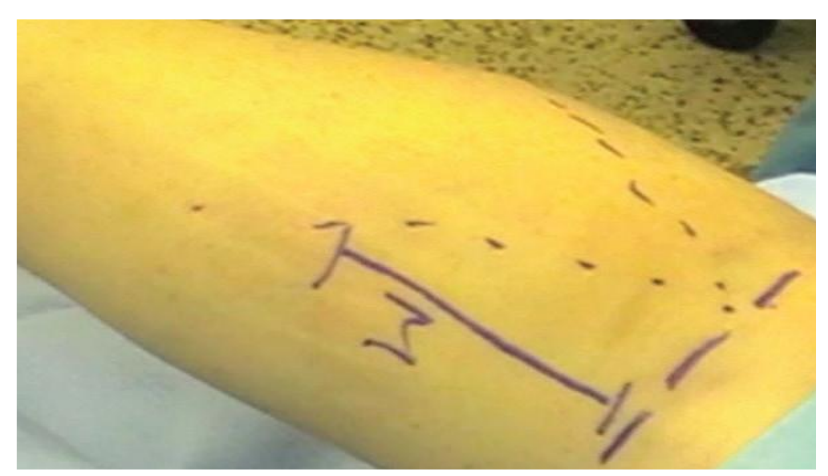

Figure (2): Surgical landmarks included the flexion crease of the knee and the medial and lateral heads of the gastrocnemius muscle (dotted lines). The posteromedial incision (solid line) is a straight vertical incision just distal to the flexion crease and on the medial side of the medial head of the gastrocnemius muscle

\section{Postoperative evaluation:}

The Knee Society Scoring System ${ }^{(18)}$ which is functional assessment containing subjective and objective, pre and postoperative assessment; was used. The scoring system was measured at one year postoperative when most patients would be expected to have reached maximal recovery; the measurements were gathered by single surgeon. Also, Accuracy of reduction of tibial plateau fragments distances.

\section{Follow up:}

Patients were evaluated radiologically immediately postoperative, at 3, 6, 12, 18 months by serial anteroposterior and lateral $\mathrm{x}$ - rays of knee. Weight bearing was allowed based upon progression of healing by radiographs. AP standing scanograms to assess mechanical axis deviation and joint orientation lines to be done at the final follow up visit.

\section{Statistical analysis:}

Data entered and analyzed using Microsoft Excel software. Data were then imported into Statistical Package for the Social Sciences (SPSS 21.0, IBM/SPSS Inc., Chicago, Illinois, USA) software for analysis. For comparison of data, ChiSquare test (or Fisher's exact test) was used to compare two independent groups of qualitative data. Correlation of numeric data was done by Pearson's or Spearman correlation (r). For all tests, $\mathrm{P}$ values $<0.05$ are considered significant.

\section{RESULTS}

The study included 4 females $(14.8 \%)$ and 23 males $(85.2 \%)$ with age range between 18-46 years with mean 33.93 \pm 7.89 of age. These data are shown in table (1).

Table (1): Demographic data distribution of the study group

\begin{tabular}{|l|c|c|}
\hline Demographic Data & No. & $\%$ \\
\hline Gender & 4 & $14.8 \%$ \\
\hline Female & 23 & $85.2 \%$ \\
\hline Male & 13 & $48.1 \%$ \\
\hline Age (years) & 14 & $51.9 \%$ \\
\hline$<35$ years & \multicolumn{3}{|l|}{} \\
\hline$\geq 35$ years & $18-46[33.93 \pm 7.89]$ \\
\hline Range [Mean \pm SD]
\end{tabular}

The results at the final follow-up showed that $18.5 \%$ of patients did not have any pain (None), $55.6 \%$ of patients had Mild
/ Occasional pain, while $11.1 \%$ of patients had Mild pain in usage of Stairs only, also11.1\% had Mild pain in Walking and 
Stairs, on the other hand $3.7 \%$ of patients had Moderate and or occasional pain; furthermore neither of patients - $(0.0 \%)$ - had Moderate and or continual pain, nor of them - $(0.0 \%)$ - had Severe of Pain. These data is shown in table (2).

Table (2): Pain distribution of the study group

\begin{tabular}{|l|c|c|}
\hline Pain & No. & $\%$ \\
\hline None (50) & 5 & $18.5 \%$ \\
\hline Mild / Occasional (45) & 15 & $55.6 \%$ \\
\hline Mild (Stairs only) (40) & 3 & $11.1 \%$ \\
\hline Mild (Walking and Stairs) (30) & 3 & $11.1 \%$ \\
\hline Moderate - occasional (20) & 1 & $3.7 \%$ \\
\hline Moderatre - continual (10) & 0 & $0.0 \%$ \\
\hline Severe (0) & 0 & $0.0 \%$ \\
\hline
\end{tabular}

At the final follow-up, $48.1 \%$ of patients did not have any flexion contracture, $44.4 \%$ of patients had $5^{\circ}-10^{\circ}$ flexion contracture, while $7.4 \%$ of patients had $10^{\circ}-15^{\circ}$ flexion contracture, on the other hand neither of patients had $16^{\circ}-20^{\circ}$ flexion contracture, nor did any have $>20^{\circ}$ flexion contracture. The data is illustrated in table (3).

Table (3): Flexion contracture (if present) distribution of the study group.

\begin{tabular}{|l|c|c|}
\hline Flexion contracture (if present) & No. & $\%$ \\
\hline None & 13 & $48.1 \%$ \\
\hline $5^{\circ}-10^{\circ}(-2)$ & 12 & $44.4 \%$ \\
\hline $10^{\circ}-15^{\circ}(-5)$ & 2 & $7.4 \%$ \\
\hline $16^{\circ}-20^{\circ}(-10)$ & 0 & $0.0 \%$ \\
\hline$>20(-15)$ & 0 & $0.0 \%$ \\
\hline
\end{tabular}

As shown in table (4), All the cases included in the study had $<10^{\circ}$ extension lag. Also, all of the patients had $<5 \mathrm{~mm}$ of antero-posterior translation. All of the patients had $<5^{\circ}$ mediolateral instability.

Table (4): Extension lag, antero-posterior stability and mediolateral stability distribution of the study group.

\begin{tabular}{|l|l|}
\hline Extension lag & Number (percent) \\
\hline$<10^{\circ}(-5)$ & $27(100 \%)$ \\
\hline $10^{\circ}-20^{\circ}(-10)$ & $0(0 \%)$ \\
\hline$>20^{\circ}(-15)$ & $0(0 \%)$ \\
\hline Antero-posterior stability & Number (percent) \\
\hline$<5 \mathrm{~mm}(10)$ & $27(100 \%)$ \\
\hline $5-10 \mathrm{~mm}(5)$ & $0(0 \%)$ \\
\hline $10+\mathrm{mm}(0)$ & $0(0 \%)$ \\
\hline Medio-lateral stability & Number (percent) \\
\hline$<5^{\circ}(15)$ & $27(100 \%)$ \\
\hline $6^{\circ}-9^{\circ}(10)$ & $0(0 \%)$ \\
\hline $10^{\circ}-14^{\circ}(5)$ & $0(0 \%)$ \\
\hline $15^{\circ}(0)$ & $0(0 \%)$ \\
\hline & \\
\hline
\end{tabular}

The results showed that: $3.7 \%$ of the patients achieved total flexion range of $86^{\circ}$ $90^{\circ}, 3.7 \%$ of the patients achieved total flexion range of $91^{\circ}-95^{\circ}$, while $18.5 \%$ of the patients achieved total flexion range of $96^{\circ}$ - $100^{\circ}, 11.1 \%$ of the patients achieved total flexion range of $106^{\circ}-110^{\circ}$; furthermore $14.8 \%$ of the patients achieved total flexion range of $111^{\circ}-115^{\circ}$ and $33.3 \%$ achieved total flexion range of $116^{\circ}-120^{\circ}$; on the otherhand 
$14.8 \%$ of the patients achieved total flexion table (5). range of $121^{\circ}-125^{\circ}$. The data is shown in

Table (5): Total range of flexion distribution of the study group

\begin{tabular}{|l|c|c|}
\hline Total range of Flexion & No. & $\%$ \\
\hline $0^{\circ}-5^{\circ}$ & 0 & $0.0 \%$ \\
\hline $6^{\circ}-10^{\circ}$ & 0 & $0.0 \%$ \\
\hline $11^{\circ}-15^{\circ}$ & 0 & $0.0 \%$ \\
\hline $16^{\circ}-20^{\circ}$ & 0 & $0.0 \%$ \\
\hline $21^{\circ}-25^{\circ}$ & 0 & $0.0 \%$ \\
\hline $26^{\circ}-30^{\circ}$ & 0 & $0.0 \%$ \\
\hline $31^{\circ}-35^{\circ}$ & 0 & $0.0 \%$ \\
\hline $36^{\circ}-40^{\circ}$ & 0 & $0.0 \%$ \\
\hline $41^{\circ}-45^{\circ}$ & 0 & $0.0 \%$ \\
\hline $46^{\circ}-50^{\circ}$ & 0 & $0.0 \%$ \\
\hline $51^{\circ}-55^{\circ}$ & 0 & $0.0 \%$ \\
\hline $56^{\circ}-60^{\circ}$ & 0 & $0.0 \%$ \\
\hline $61^{\circ}-65^{\circ}$ & 0 & $0.0 \%$ \\
\hline $66^{\circ}-70^{\circ}$ & 0 & $0.0 \%$ \\
\hline $71^{\circ}-75^{\circ}$ & 0 & $0.0 \%$ \\
\hline $67^{\circ}-80^{\circ}$ & 0 & $0.0 \%$ \\
\hline $81^{\circ}-85^{\circ}$ & 0 & $0.0 \%$ \\
\hline $86^{\circ}-90^{\circ}$ & 1 & $3.7 \%$ \\
\hline $91^{\circ}-95^{\circ}$ & 1 & $3.7 \%$ \\
\hline $96^{\circ}-100^{\circ}$ & 5 & $18.5 \%$ \\
\hline $101^{\circ}-105^{\circ}$ & 0 & $0.0 \%$ \\
\hline $106^{\circ}-110^{\circ}$ & 3 & $11.1 \%$ \\
\hline $111^{\circ}-115^{\circ}$ & 4 & $14.8 \%$ \\
\hline $116^{\circ}-120^{\circ}$ & 9 & $33.3 \%$ \\
\hline $121^{\circ}-125^{\circ}$ & 4 & $14.8 \%$ \\
\hline
\end{tabular}

The results showed that $3.7 \%$ of the patients had $2^{\circ}$ of varus alignment, $37 \%$ had $3^{\circ}$ of varus alignment, while only $7.4 \%$ had $4^{\circ}$ of varus alignment, the majority of

Table (6): Alignment (varus \& valgus) distribution of the study group

\begin{tabular}{|l|c|c|}
\hline Alignment (Varus \& Valgus) & No. & $\%$ \\
\hline $0^{\circ}$ & 0 & $0.0 \%$ \\
\hline $1^{\circ}$ & 0 & $0.0 \%$ \\
\hline $2^{\circ}$ & 1 & $3.7 \%$ \\
\hline $3^{\circ}$ & 10 & $37.0 \%$ \\
\hline $4^{\circ}$ & 2 & $7.4 \%$ \\
\hline $5^{\circ}-10^{\circ}$ & 14 & $51.9 \%$ \\
\hline $11^{\circ}$ & 0 & $0.0 \%$ \\
\hline $12^{\circ}$ & 0 & $0.0 \%$ \\
\hline $13^{\circ}$ & 0 & $0.0 \%$ \\
\hline $14^{\circ}$ & 0 & $0.0 \%$ \\
\hline $15^{\circ}$ & 0 & $0.0 \%$ \\
\hline${\text { Over } 15^{\circ}}^{\circ}$ & 0 & $0.0 \%$ \\
\hline
\end{tabular}

The results showed that $37.0 \%$ of the patients showed Unlimited walking ability, the majority of patients $(55.6 \%)$ showed walking ability $>10$ blocks, $7.4 \%$ of the patients $(51.9 \%)$ had $5^{\circ}-10^{\circ}$ varus alignment and none had valgus alignment. These data are illustrated in table (6). 
was unable to walk. The results showed that: $40.7 \%$ of patients showed normal up and down stairs usage, the majority of patients $51.9 \%$ - showed normal up down with rail stairs usage, while $7.4 \%$ of patients showed up and down with rail stairs usage; neither of the patients showed up with rail down unable stairs usage. None of them was unable to use the stairs. The majority of patients $(74.1 \%)$ did not use any walking aids, $25.9 \%$ of patients used Cane/Walking stick, and none of the patients used crutches or frame. These data is illustrated in table (7).

Table (7): Walking distribution of the study group.

\begin{tabular}{|l|c|c|}
\hline Walking & No. & $\%$ \\
\hline Unlimited & 10 & $37.0 \%$ \\
\hline$>10$ blocks & 15 & $55.6 \%$ \\
\hline $5-10$ blocks & 2 & $7.4 \%$ \\
\hline$<5$ blocks & 0 & $0.0 \%$ \\
\hline Housebound & 0 & $0.0 \%$ \\
\hline Unable & 0 & $0.0 \%$ \\
\hline Stairs & No. & $\%$ \\
\hline Normal Up and down & 11 & $40.7 \%$ \\
\hline Normal Up down with rail & 14 & $51.9 \%$ \\
\hline Up and down with rail & 2 & $7.4 \%$ \\
\hline Up with rail down unable & 0 & $0.0 \%$ \\
\hline Unable & 0 & $0.0 \%$ \\
\hline Walking aids used & No. & $\%$ \\
\hline None used & 20 & $74.1 \%$ \\
\hline Use of Cane/Walking stic deducted & 7 & $25.9 \%$ \\
\hline Two Canes/sticks & 0 & $0.0 \%$ \\
\hline Crutches or frame & 0 & $0.0 \%$ \\
\hline
\end{tabular}

The overall score results were excellent result. These data are illustrated in table in $70.4 \%$, good in $25.9 \%$, fair in $3.7 \%$ of the (8). patients. None of the patients showed poor Table (8): Knee society score distribution of the study group

\begin{tabular}{|l|l|l|}
\hline Knee society score & No. & $\%$ \\
\hline Poor below 60 & 0 & $0.0 \%$ \\
\hline Fair 60-69 & 1 & $3.7 \%$ \\
\hline Good 70-79 & 7 & $25.9 \%$ \\
\hline Excellent 80-100 & 19 & $70.4 \%$ \\
\hline Range [Mean \pm SD] & $68-92[82.56 \pm 6.08]$ \\
\hline
\end{tabular}

The results showed that $7.4 \%$ of the patients had a score of $70,18.5 \%$ of the patients had a score of 75 , while $29.6 \%$ of the patients had a score of 80 , only $3.7 \%$ of the patients had a score of 85 ; in addition to $11.1 \%$ of the patients had a score of 90 , $3.7 \%$ of the patients had a score of 95 , and $25.9 \%$ of the patients had a score of 100 . 
Table (9): Function score KSS distribution of the study group

\begin{tabular}{|l|c|c|}
\hline Function score KSS & No. & $\%$ \\
\hline 70 & 2 & $7.4 \%$ \\
\hline 75 & 5 & $18.5 \%$ \\
\hline 80 & 8 & $29.6 \%$ \\
\hline 85 & 1 & $3.7 \%$ \\
\hline 90 & 3 & $11.1 \%$ \\
\hline 95 & 1 & $3.7 \%$ \\
\hline 100 & 7 & $25.9 \%$ \\
\hline Range [Mean \pm SD] & \multicolumn{2}{|c|}{$70-80[85.37 \pm 10.55]$} \\
\hline
\end{tabular}

There was no statistically significant relation between knee society score and age difference in the knee society score between of the study group was statistically males and females. On the other hand, the significant

Table (10): Relation between knee society score according to sex of the study group.

\begin{tabular}{|c|c|c|c|c|c|c|c|c|}
\hline \multirow[t]{3}{*}{ Sex } & \multicolumn{6}{|c|}{ Knee society score } & \multirow{2}{*}{\multicolumn{2}{|c|}{ Chi-square test }} \\
\hline & \multicolumn{2}{|c|}{ Fair 60-69 } & \multicolumn{2}{|c|}{ Good 70-79 } & \multicolumn{2}{|c|}{ Excellent 80-100 } & & \\
\hline & No. & $\%$ & No. & $\%$ & No. & $\%$ & $\mathrm{x} 2$ & $\mathrm{p}$-value \\
\hline \multicolumn{9}{|l|}{ Sex } \\
\hline Female & 0 & $0.0 \%$ & 1 & $3.7 \%$ & 3 & $11.1 \%$ & \multirow[t]{3}{*}{0.19} & \multirow[t]{3}{*}{0.909} \\
\hline Male & 1 & $3.7 \%$ & 6 & $22.2 \%$ & 16 & $59.3 \%$ & & \\
\hline Total & 1 & $3.7 \%$ & 7 & $25.9 \%$ & 19 & $70.4 \%$ & & \\
\hline \multicolumn{9}{|l|}{ Age group } \\
\hline$<35$ years & 0 & $0.0 \%$ & 1 & $3.7 \%$ & 12 & $44.4 \%$ & \multirow[t]{3}{*}{5.858} & \multirow[t]{3}{*}{$0.043 *$} \\
\hline$\geq 35$ years & 1 & $3.7 \%$ & 6 & $22.2 \%$ & 7 & $25.9 \%$ & & \\
\hline Total & 1 & $3.7 \%$ & 7 & $25.9 \%$ & 19 & $70.4 \%$ & & \\
\hline
\end{tabular}

P-value $>0.05 \mathrm{NS}$

The results showed statistically with final knee society score and function significant negative correlation between age score KSS of the study group.

Table (11): Correlation between age with final knee society score and function score KSS of the study group.

\begin{tabular}{|l|c|c|}
\hline \multirow{2}{*}{} & \multicolumn{2}{|c|}{ Age (years) } \\
\cline { 2 - 3 } & r & p-value \\
\hline Final knee society score & -0.385 & $0.047^{*}$ \\
\hline Function score KSS & -0.381 & $0.049^{*}$ \\
\hline
\end{tabular}

\section{DISCUSSION:}

Generally, complex and high energy intraarticular fractures of the weight bearing lower extremity represent a management challenge and a decision-making dilemma to the orthopedic surgeon $^{(19,20,21,22)}$. Several studies have overemphasized the importance of accurate restoration of articular cartilage congruity and suggested an association betweenitand functional improve-ment ${ }^{(19,21,22)}$. However, other authors have linked functional outcome and subsequent osteoarthritis to the initial cartilage injury ${ }^{(20)}$.

The current prospective clinical study reports the results of posterior intervention for tibial plateau fractures. Our cohort of patients comprised of 27 consecutive patients who had fractures of the tibial plateau with posterior column involvement. Average follow up was 18 months. Postoperative objective knee society score was 82.56 (68-92), functional knee society score 
was 85.37 (70-80), 4 were females, 23 were males, mean age was 33.93(18-46). In this study, 11 patients had posterior plate fixation and 16 patients had dual plate fixation.

In the study of $\mathrm{Yu}$ et al (2009), 54 patients with high energy tibial plateau fractures were reviewed. Average follow-up was 23.7 months Post-operative objective knee society score was 70.3 (39-91), 21 were females, 33 were males, mean age was 45.2 (19-68) all 54 pateints had dual plate fixation ${ }^{(21)}$. $\mathrm{Yu}$ et al. reported at the final clinical follow up that no patient showed knee instability, and the mean range of motion was $107.6^{\circ}\left(85^{\circ}-130^{\circ}\right){ }^{(21)}$. There were 9 cases suffering from stiffness of knee joint, 3 cases of varus abnormity, 2 cases of valgus abnormity, 2 cases of incisional wound infection (debridement and External fixation were performed with internal implants removed), 10 cases of traumatic arthritis of knee joint ( 2 cases received the total knee arthroplasty 1 year and 2 years postoperatively, and the other 8 cases did not receive any further operation during the follow-up periods), and 1 case of delayed union. $\mathrm{Yu}$ et al. concluded that Doublebuttress plate fixation is a feasible treatment option for bicondylar and complex tibial plateau fractures. Although technically demanding, it offers reliable stability without additional postoperative adjuvant external fixation and at the same time avoids extensive soft tissue dissection, allowing the early painless range of motion ${ }^{(21)}$.

In the study of Citakaner et al (2019), 10 patients with high energy tibial plateau fractures were reviewed. Average follow-up was 24 months Post-operative objective knee society score was 79.1 (49-100) 3 were females, 7 were males, mean age was 51.2 (25-83) all ten patients had dual plate fixation ${ }^{(22)}$.Citakaner et al. had one case of superficial surgical site infection which resolved with antibiotic therapy and wound care 6 cases of late postoperative complication in the form of arthrosis with no single case of non-union ${ }^{(22)}$.Catakaner et al. concluded that Dual locking plate fixation technique and lateral locking plate fixation technique are effective methods in the treatment of bicondylar tibial plateau fractures when used properly. The lateral locking plate fixation technique may provide comparable clinical and radiological outcomes with dual locking plate fixation technique for the treatment of bicondylar plateau fractures without posteromedial fragment ${ }^{(22)}$.

In the study of Sinha et al (2019), 30 patients with high energy tibial plateau fractures were reviewed. Average follow-up was 10.9 months Post-operative objective knee society score was 85.4 (69-100) functional knee society score was 81 (75-90) ${ }^{(23)}$.In this study, 2 were females, 28 were males, mean age was 41.5 (20-60). All 30 patients had dual plate fixation. Sinha et al. reported two patients developed deep wound infection. One patient recovered with antibiotics, but the other required regular debridement and finally removal of implant $^{(23)}$. Sinha et al. concluded that Addition of posterior approach for stabilization of the posterior fragment in posterior tibial plateau fractures achieves early and improved knee Functions, good range of movements, minimal deformities, and pain scores by the time fracture unites, However, peri-operative morbidity, extraimplant costs and increased operative time are its disadvantages. Another patient developed wound dehiscence initially that healed after responding to oral antibiotics.

A prominent lateral plate was seen in two patients, which was not causing any clinical problem. Articular mal reduction was observed in one patient, but his functional scoring was acceptable with good range of movement. 
Table (12): Summary of the different studies

\begin{tabular}{|c|c|c|c|c|}
\hline Study & Caner et al. 2019 & Yu et al. 2009 & Sinha et al. 2019 & Current study 2019 \\
\hline $\begin{array}{l}\text { No. of } \\
\text { patients }\end{array}$ & 10 & 54 & 30 & 27 \\
\hline $\begin{array}{l}\text { Mean } \\
\text { duration of } \\
\text { follow up } \\
\text { (months) }\end{array}$ & 24 & $23.7(12-48)$ & $10.9(7-15)$ & 18 \\
\hline KSS & $79.1(49-100)$ & $70.3(39-91)$ & $\begin{array}{l}\text { Objective assessment } \\
85.4(68-100) \\
\text { Functional assessment } \\
81(75-90)\end{array}$ & $\begin{array}{l}\text { Objective assessment } \\
82.56(68-92) \\
\text { Functional assessment } \\
85.37(70-80)\end{array}$ \\
\hline Technique & $\begin{array}{l}\text { Dual plating } \\
\text { Posteromedial } \\
\text { anterolateral } \\
\text { patients }\end{array}$ & $\begin{array}{l}\text { Dual plating } \\
\text { Posteromedial } \\
\text { and anterolateral } \\
\text { all patients }\end{array}$ & $\begin{array}{l}\text { Dual plating } \\
\text { Posteromedial and } \\
\text { anterolateral all } \\
\text { patients }\end{array}$ & $\begin{array}{lll}\text { Posteromedial } & \text { only } & 11 \\
\text { patients } & & \\
\text { Posteromedial } & & \text { and } \\
\text { anterolateral 16 } & & \\
\end{array}$ \\
\hline Female & 3 & 21 & 2 & 4 \\
\hline Males & 7 & 33 & 28 & 23 \\
\hline Right & 5 & 25 & 20 & 14 \\
\hline Left & 5 & 29 & 10 & 13 \\
\hline Age & $51.2(25-83)$ & $45.2(19-68$ & $41.5(20-60)$ & $33.93(18-46)$ \\
\hline
\end{tabular}

Three case of complication were reported in the form of wound infection which responded to oral antibiotics and wound care without extra surgery.

Our post-operative KSS was comparable to other studies although our mean age of patients was younger (33.93) all of the studies had cases of post-operative wound infections which highlights the necessity of proper timing of surgical intervention and meticulous wound care postoperatively.

\section{Conclusion:}

Posterior approaches to tibial plateau fractures whether alone or combined with other approaches was associated with good clinical and radiologic outcomes along the duration of postoperative follow up and should be advised as an alternative for management of tibial plateau fractures.

\section{Conflict of Interest}

Authors declare no conflicts of interest.

\section{REFERENCES}

1. 1.Muller M, Allgower M, Schneider R, Willenegger $H$. Patella and tibia. Ed. 1979;2:553-94.
2. 2.Schatzker J. Tibial plateau fractures. Skeletal trauma Fractures, dislocations, ligamenteous injuries. 1992;2.

3. 3.Krieg JC. Proximal tibial fractures: current treatment, results, and problems. Injury. 2003;34:A2-10.

4. 4.Barei DP, Nork SE, Mills WJ, Henley MB, Benirschke SK. Complications associated with internal fixation of highenergy bicondylar tibial plateau fractures utilizing a two-incision technique. Journal of orthopaedic trauma. 2004;18(10):649-57.

5. 5.Weil YA, Gardner MJ, Boraiah S, Helfet DL, Lorich DG. Posteromedial supine approach for reduction and fixation of medial and bicondylar tibial plateau fractures. Journal of orthopaedic trauma. 2008;22(5):357-62.

6. 6.Barei DP, O'Mara TJ, Taitsman LA, Dunbar RP, Nork SE. Frequency and fracture morphology of the posteromedial fragment in bicondylar tibial plateau fracture patterns. Journal of orthopaedic trauma. 2008;22(3):176-82.

7. 7.Luo C-F, Jiang R, Hu C-F, Zeng B-F. Medial double-plating for fracture dislocations involving the proximal tibia. The knee. 2006;13(5):389-94. 
8. 8.Wicky S, Blaser P, Blanc C, Leyvraz P, Schnyder P, Meuli R. Comparison between standard radiography and spiral $\mathrm{CT}$ with $3 \mathrm{D}$ reconstruction in the evaluation, classification and management of tibial plateau fractures. European radiology. 2000;10(8):1227-32.

9. 9.Zhu Y, Yang G, Luo C-F, Smith WR, Hu $\mathrm{C}-\mathrm{F}$, Gao H, et al. Computed tomographybased Three-Column Classification in tibial plateau fractures: introduction of its utility and assessment of its reproducibility. Journal of Trauma and Acute Care Surgery. 2012;73(3):731-7.

10. 10.Luo C-F, Sun H, Zhang B, Zeng B-F. Three-column fixation for complex tibial plateau fractures. Journal of orthopaedic trauma. 2010;24(11):683-92.

11. 11.Eggli S, Hartel MJ, Kohl S, Haupt U, Exadaktylos AK, Röder C. Unstable bicondylar tibial plateau fractures: a clinical investigation. Journal of orthopaedic trauma. 2008;22(10):673-9.

12. 12.Stahel PF. Direct Posterior Approach for Treatment of Posteromedial Fractures of the Tibial Plateau. 2014.

13. 13.Solomon LB, Stevenson AW, Baird RP, Pohl AP. Posterolateral transfibular approach to tibial plateau fractures: technique, results, and rationale. Journal of orthopaedic trauma. 2010;24(8):505-14.

14. 14.Frosch K-H, Balcarek $P$, Walde $T$, Stürmer KM. A new posterolateral approach without fibula osteotomy for the treatment of tibial plateau fractures. Journal of orthopaedic trauma. 2010;24(8):515-20.

15. 15.Oestern $\mathrm{H}, \quad$ Tscherne $\mathrm{H}$. Pathophysiologie und Klassifikation des Weichteilschadens. Hefte Unfallheilkd. 1983;162(1).

16. 16.Valderrama-Molina CO, EstradaCastrillón M, Hincapie JA, Lugo-Agudelo LH. Intra-and interobserver agreement on the Oestern and Tscherne classification of soft tissue injury in periarticular lower-limb closed fractures. Colombia Médica. 2014;45(4):173-8.

17. 17.Lobenhoffer $\mathrm{P}$, Gerich $\mathrm{T}$, Bertram $\mathrm{T}$, Lattermann C, Pohlemann T, Tscheme H. Particular posteromedial and posterolateral approaches for the treatment of tibial head fractures. Der Unfallchirurg. 1997;100(12):957-67.

18. 18.Insall JN, Dorr LD, Scott RD, Scott WN. Rationale of the Knee Society clinical rating system. Clin Orthop relat res. 1989;248(248):13-4.

19. 19.Rayan A, Kotb A, Elmoatasem EM, Samir S, EL-Sobky TA., El-Hawi E, et al. Open reduction internal fixation versus external fixation with limited internal fixation for displaced comminuted closed pilon fractures: A randomised prospective study. J Orthop Trauma Rehabil 2018; 24 : 84-89

20. 20.Sommer C, Chen MS, Espinoza K, Joeris A, Voegtli D, Stoffel K. The influence of initial cartilage damages in pilon fractures on the development of osteoarthritis and functional outcomes: A prospective multicentre case series. J Musculoskelet Surg Res. 2019;3:334-41

21. 21.Yu Z, Zheng L, Zhang Y, Li J, Ma B. Functional and radiological evaluations of high-energy tibial plateau fractures treated with double-buttress plate fixation. European journal of medical research. 2009;14(5):200.

22. 22.Citak C, Kayali C, Ozan F, Altay T, Karahan HG, Yamak K. Lateral Locked Plating or Dual Plating: A Comparison of Two Methods in Simple Bicondylar Tibial Plateau Fractures. Clinics in orthopedic surgery. 2019;11(2):151-8.

23. 23.Sinha S, Singh M, Saraf SK, Rastogi A, Rai AK, Singh TB. Fixation of posterior tibial plateau fracture with additional posterior plating improves early rehabilitation and patient satisfaction. Indian journal of orthopaedics. 2019;53(3):472. 
تقييم نتائج التذخل الجراحي الخلفي لكسور الجزء الخلفي لأعلي عظمه الظنبوب: دراسة لسلسة حالات

\author{
التمامى م. سليمان ر. القرش م. مهر ان م.السبكي ت التمان

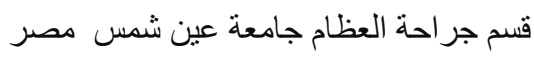 \\ محمود التمامى
}

المقدمة :معالجة الكسور المتقدمة للسطح المفصلى لأعلي عظمه الظنبوب تمثل تحدي اكلينيكي. في السنوات القيلي القليله

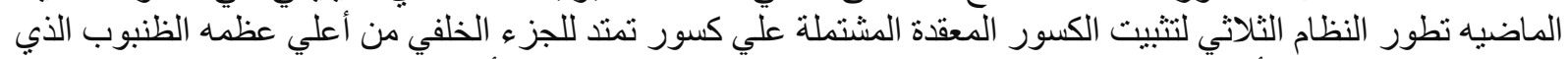

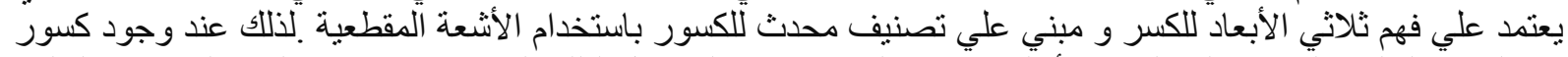

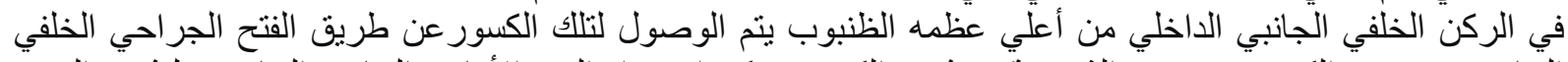

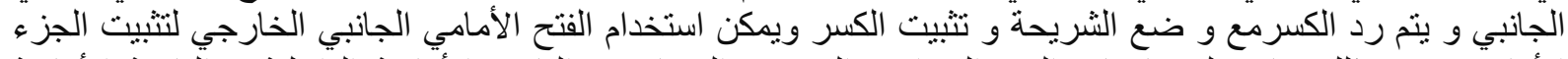

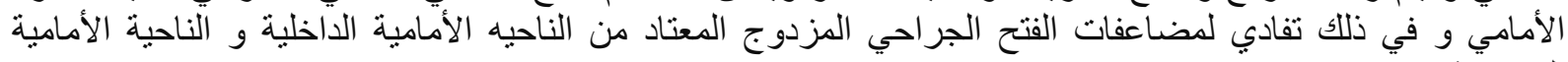
الخارجية.

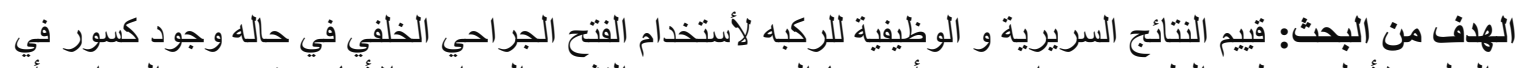

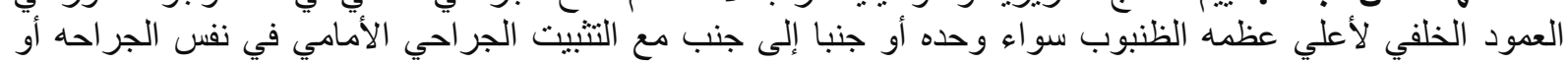
بالتتابع . المرضى وطرق العلاج:در اسة تضم Vات من المرضى الذين يعانون من كسور في أعلي عظام الساق بمشاركة العمود

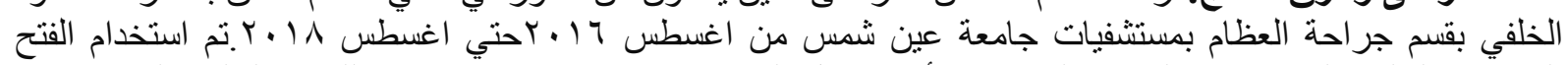

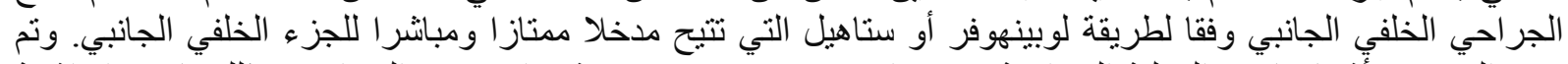

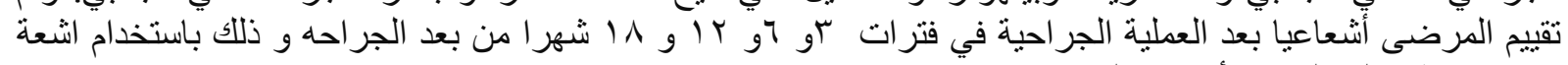

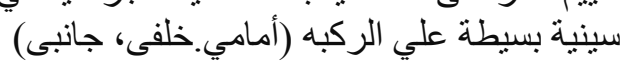

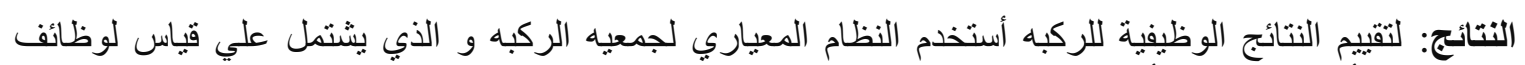

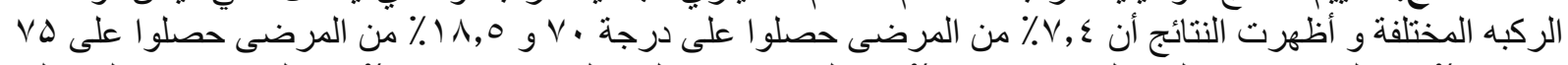

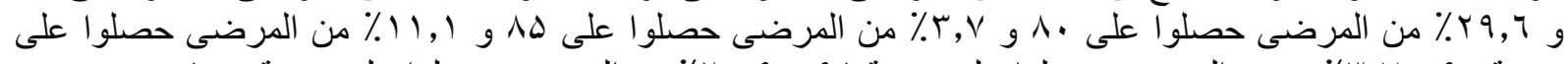

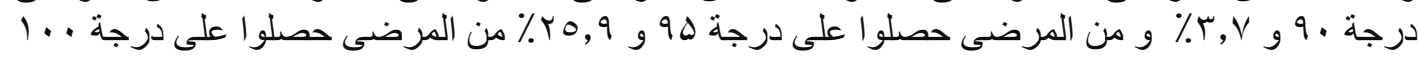

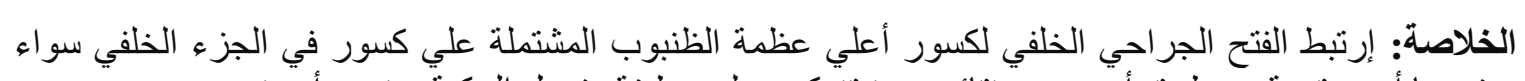

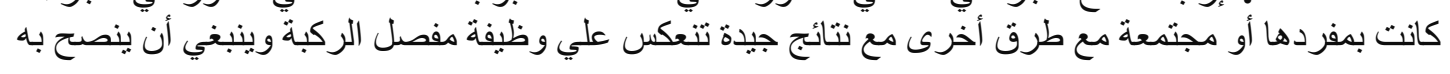

